\title{
Ceria nanoparticles supported on carbon nanotubes for the removal of arsenate from water
}

\author{
Xianjia Peng ${ }^{\mathrm{a}}$, Zhaokun Luan ${ }^{\mathrm{a}, *}$, Jun Ding ${ }^{\mathrm{b}}$, Zechao $\mathrm{Di}^{\mathrm{b}}$, Yanhui $\mathrm{Li}^{\mathrm{b}}$, Binghui $\operatorname{Tian}^{\mathrm{a}}$ \\ ${ }^{a}$ State Key Laboratory of Environmental Aquatic Chemistry, Research Center for Eco-Environmental Sciences, \\ Chinese Academy of Sciences, Beijing 100085, China \\ ${ }^{\mathrm{b}}$ Department of Mechanical Engineering, State Key Laboratory of Automotive Safety and Energy, Tsinghua University, Beijing 100084, China
}

Received 14 October 2003; accepted 12 May 2004

Available online 21 October 2004

\begin{abstract}
A novel adsorbent, ceria supported on carbon nanotubes $\left(\mathrm{CeO}_{2}-\mathrm{CNTs}\right)$, was developed for the removal of arsenate from water. The experiments show that $\mathrm{CeO}_{2}$-CNTs is an effective adsorbent for arsenate, and the adsorption is $\mathrm{pH}$-dependent. $\mathrm{Ca}^{2+}$ and $\mathrm{Mg}^{2+}$ significantly enhanced its adsorption capacity, which suggests that it is a promising adsorbent for drinking water purification. Under natural pH conditions, an increase from 0 to $10 \mathrm{mg} / \mathrm{L}$ in the concentration of $\mathrm{Ca}^{2+}$ and $\mathrm{Mg}^{2+}$ results in an increase from 10 to 81.9 and $78.8 \mathrm{mg} / \mathrm{g}$ in the amount of $\mathrm{As}(\mathrm{V})$ adsorbed, respectively. The loaded adsorbent can be efficiently regenerated by diluted $\mathrm{NaOH}$, and a regeneration efficiency of $94 \%$ was achieved using $0.1 \mathrm{~mol} / \mathrm{L} \mathrm{NaOH}$. The adsorption mechanism was also suggested.
\end{abstract}

(C) 2004 Elsevier B.V. All rights reserved.

Keywords: Nanomaterials; X-ray techniques; Surfaces; Adsorbent; Water treatment; Arsenate

\section{Introduction}

Since Iijima's observations in 1991 [1], carbon nanotubes (CNTs) have been the subject of an increasing number of experimental and theoretical studies. CNTs have unique mechanical, electrical, optical, and thermal properties and can be used to prepare novel materials, such as hydrogen storage materials [2], superconductors [3], reinforced materials [4], etc. Their cylindrically layered and hollow tubule nanostructures with high thermal and chemical stabilities make them possible to function as supports for preparing nanosized metal and metal oxide particle catalysts. Many kinds of metals have been successfully supported on CNTs [5-7]. Because of their large specific area, CNTs can also be used as supports for adsorption materials. In this paper, ceria supported on CNTs was prepared as a novel adsorbent for the removal of arsenate in water purification.

\footnotetext{
* Corresponding author. Tel./fax: +86 1062849198

E-mail address: luanzk@mail.rcees.ac.cn (Z. Luan).
}

Arsenic pollution of water occurs due to various reasons, such as natural leaching of rocks containing arsenic, mining, processing of mineral deposits and discharge of industrial pollutants [8]. Although arsenic is needed as a micronutrient for human body, it is carcinogenic when consumed in larger quantities over a period. Hence, it is of great importance to remove arsenic before water can be used for drinking in arsenic-contaminated areas. Adsorption is one of the major methods employed for the removal of arsenic from water. Many kinds of adsorbents, such as carbon, rare earth oxides, lanthanum and yttrium impregnated alumina, amorphous iron hydroxide, polymers loaded with monoclinic hydrous zirconium oxide, ion exchange fiber, and lanthanum compounds, have been developed for the removal of arsenic from water [8-13]. Ceria has been reported to have good adsorption capacity for the removal of some anions and high resistance against attacks by acid [14]. Otherwise, cerium is a rather cost-effective element with rather large reserves among rare earth elements. Here, ceria was supported on carbon nanotubes as nanoparticles, and the resulting 
material was reported to have good arsenate adsorption capacity from water in this paper.

\section{Experimental}

\subsection{Materials}

CNTs were prepared by catalytic pyrolysis of the propylene-hydrogen $\left(\mathrm{C}_{3} \mathrm{H}_{6} / \mathrm{H}_{2}=2: 1\right)$ mixture at $750{ }^{\circ} \mathrm{C}$ in a ceramic tube furnace using $\mathrm{Ni}$ particles as catalysts. The CNTs were then washed with deionized water and ground. The oxidized CNTs were prepared by refluxing the asprepared CNTs with mixed solution of nitric acid and sulfuric acid at $140{ }^{\circ} \mathrm{C}$ to introduce oxygen groups, such as hydroxyl $(-\mathrm{OH})$ and carboxyl $(-\mathrm{COOH})$, on the surface of CNTs. These groups can preserve the suspensibility of CNTs in solution and may be beneficial to the adhesion of $\mathrm{Ce}(\mathrm{OH})_{3}$ particles on the wall of CNTs. The ceria supported on carbon nanotubes was prepared as follows [7]: $1 \mathrm{~g}$ CNTs were dispersed into $20 \mathrm{~mL}$ distilled water and agitated with a magnetic agitator. The $\mathrm{CeCl}_{3}$ $(0.035 \mathrm{~g} / \mathrm{mL})$ solution was added into the CNTs solution drop by drop. After the mixture was agitated for $1 \mathrm{~h}, 0.5$ wt.\% $\mathrm{NaOH}$ was titrated into the mixture until the $\mathrm{pH}$ value reaches 9. The mixture was then dried up and heated in air at $450{ }^{\circ} \mathrm{C}$ for $20 \mathrm{~min}$ to oxidize $\mathrm{Ce}(\mathrm{OH})_{3}$ particles to $\mathrm{CeO}_{2}$ nanoparticles. The nanosized ceria particles supported on CNTs can be prepared. Stock solution of $1000 \mathrm{mg} / \mathrm{L} \mathrm{As}(\mathrm{V})$ was prepared by dissolving appropriate quantities of analytical grade dibasic sodium arsenate in deionized water. The stock solution was further diluted to suitable concentrations.

\subsection{Methods}

Zeta potential and points of zero charge (PZC) for the adsorbent were determined by microelectrophoresis using a Malven model Zetasizer 2000 zeta potential analyzer. The zeta potentials of the adsorbent suspensions containing $0.02 \%$ solid in $0.01 \mathrm{M} \mathrm{NaCl}$ were determined at various $\mathrm{pH}$ values. The PZCs were obtained by interpolating the data to zero zeta potential. The specific area of the adsorbents was measured by nitrogen adsorption/desorption at $77 \mathrm{~K}$ using BET method.

Batch adsorption experiments were performed in glass bottles. To each bottle, $50 \mathrm{~mL} A s(\mathrm{~V})$ solution of prescribed concentration and $0.025 \mathrm{~g}$ adsorbent were added. The $\mathrm{pH}$ was adjusted using $1 \mathrm{M} \mathrm{HCl}$ or $1 \mathrm{M}$ $\mathrm{NaOH}$. The bottles were capped with glass screws and then were shaken on a HZQ-C shaker for $24 \mathrm{~h}$. After equilibrium, the solution was centrifuged and the residual concentrations of $\mathrm{As}(\mathrm{V})$ in the supernatant solution was analyzed using a Rayleigh model AF-610A atomic fluorescence spectrometer. As(V) adsorbed was calculated. Desorption experiments using $\mathrm{NaOH}$ and $\mathrm{HCl}$ were carried out. For desorption experiments, first $\mathrm{As}(\mathrm{V})$ was adsorbed according to the same procedure described above. After adsorption, suspensions were centrifuged. The supernatant was decanted and analysed for $\mathrm{As}(\mathrm{V})$. Then $50 \mathrm{~mL}$ of $\mathrm{NaOH}$ or $\mathrm{HCl}$ solution $(0.005-0.05 \mathrm{M})$ was added to the loaded particles. The samples were then shaken for $2 \mathrm{~h}$ and centrifuged. $\operatorname{As}(\mathrm{V})$ concentration in the supernatant was analyzed, and regeneration efficiency was calculated.

\section{Results and discussion}

The X-ray diffraction (XRD) pattern and transmission electron microscopy (TEM) image of ceria supported on CNTs $\left(\mathrm{CeO}_{2}\right.$-CNTs $)$ are shown in Figs. 1 and 2. There are two peaks corresponding to the (002) and the (101) of CNTs in the XRD pattern, and it shows that the nanosized ceria particle and the CNTs possess good crystalline structures. The TEM image show that ceria particles are homogeneously spread on the surface of CNTs with a particle size of about $6 \mathrm{~nm}$. The specific area of oxidized CNTs and $\mathrm{CeO}_{2-}$ CNTs are $153 \mathrm{~m}^{2} / \mathrm{g}$ and $189 \mathrm{~m}^{2} / \mathrm{g}$, respectively. It indicates that the deposition of nanosized particles of ceria increases the surface area.

The zeta potentials of $\mathrm{CeO}_{2}-\mathrm{CNT}$ at various $\mathrm{pH}$ were shown in Fig. 3. For comparison, Zeta potentials of oxidized CNTs were also included. As can be seen from Fig. 3, Zeta potentials of both $\mathrm{CeO}_{2}$-CNTs and oxidized CNTs decrease with the increase in $\mathrm{pH}$. $\mathrm{CeO}_{2}-\mathrm{CNTs}$ have positive Zeta potentials when $\mathrm{pH}<5.5$, which indicates that they are positively charged, and negative Zeta potentials when $\mathrm{pH}>6.4$, which indicates that they are negatively charged. The PZC of $\mathrm{CeO}_{2}$-CNTs occurs at $\mathrm{pH}$ 5.5-6.4. Zeta potentials of oxidized CNTs remain negative in the $\mathrm{pH}$ range $\sim 3-\sim 10$, which indicates that they are negatively charged. $\mathrm{As}(\mathrm{V})$ exists as anions in aqueous solution. The electrostatic interaction between oxidized CNTs and As(V) anions is repulsion, which decreases the adsorption. During the $\mathrm{pH}$ range of $\sim 3-\sim 10, \mathrm{CeO}_{2}$-CNTs have much higher Zeta potentials than oxidized CNTs. The increased Zeta

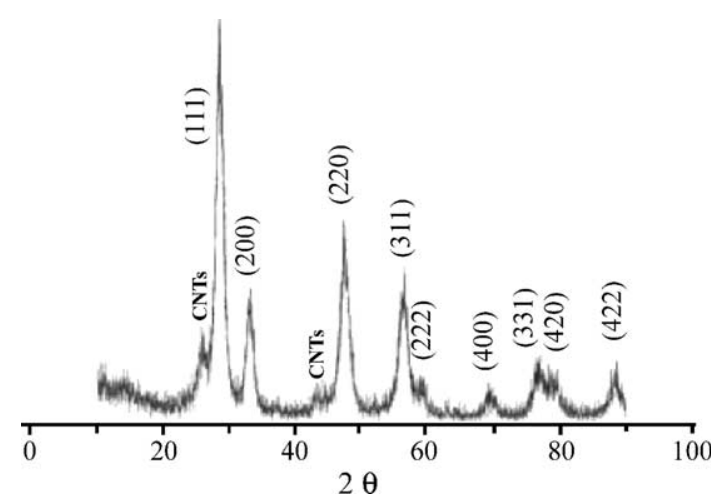

Fig. 1. XRD pattern of $\mathrm{CeO}_{2}$-CNTs. 


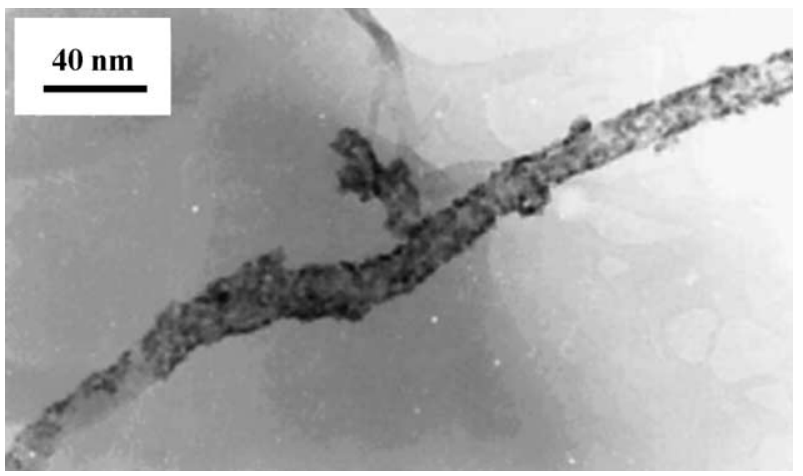

Fig. 2. TEM image of $\mathrm{CeO}_{2}-\mathrm{CNTs}$.

potential resulting from the deposition of ceria on oxidized CNTs can be expected to decrease the electrostatic repulsion. Moreover, at $\mathrm{pH}<\mathrm{PZC}$, the electrostatic interaction between positively charged $\mathrm{CeO}_{2}-\mathrm{CNTs}$ and $\mathrm{As}(\mathrm{V})$ anions is attraction. The electrostatic attraction can facilitate the adsorption.

The effect of $\mathrm{pH}$ on the adsorption of $\mathrm{As}(\mathrm{V})$ to $\mathrm{CeO}_{2}$ CNTs is shown in Fig. 4. For comparison, the use of oxidized CNTs for As(V) adsorption was also included. Fig. 4 shows that the adsorption of $\mathrm{As}(\mathrm{V})$ to $\mathrm{CeO}_{2}-\mathrm{CNTs}$ is $\mathrm{pH}-$ dependent. $\mathrm{CeO}_{2}$-CNTs have higher adsorption capacity than oxidized CNTs. Adsorption of $\mathrm{As}(\mathrm{V})$ to $\mathrm{CeO}_{2}-\mathrm{CNTs}$ decreases with the increase in $\mathrm{pH}$. An increase in $\mathrm{pH}$ from 3.1 to 10.0 results in a decrease from 19.7 to $8.7 \mathrm{mg} / \mathrm{g}$ in the amount of $\mathrm{As}(\mathrm{V})$ adsorbed. The dependence of adsorption on $\mathrm{pH}$ values is due to the dependence of the surface charge of $\mathrm{CeO}_{2}$-CNTs on $\mathrm{pH}$ values, which has been shown by Zeta potential measurements. At $\mathrm{pH}<\mathrm{PZC}$, the surface charge of $\mathrm{CeO}_{2}-\mathrm{CNTs}$ is positive, and coulombic attraction can readily take place between the positively charged adsorbent particles and negatively charged $\mathrm{As}(\mathrm{V})$ ions. Adsorption of $\mathrm{As}(\mathrm{V})$ decreases at $\mathrm{pH}>\mathrm{PZC}$ due to negatively charged adsorbent surface. Many researchers [9,13,15-17] have found that the adsorption of anions is the reaction between anions and the $-\mathrm{MOH}$ or $-\mathrm{MOH}_{2}^{+}$on the adsorbent surface. The hydroxylation of cerium oxides supported on $\mathrm{CNT}$ s can form $-\mathrm{Ce}-\mathrm{OH}$ and $-\mathrm{Ce}-\mathrm{OH}_{2}^{+}$on the

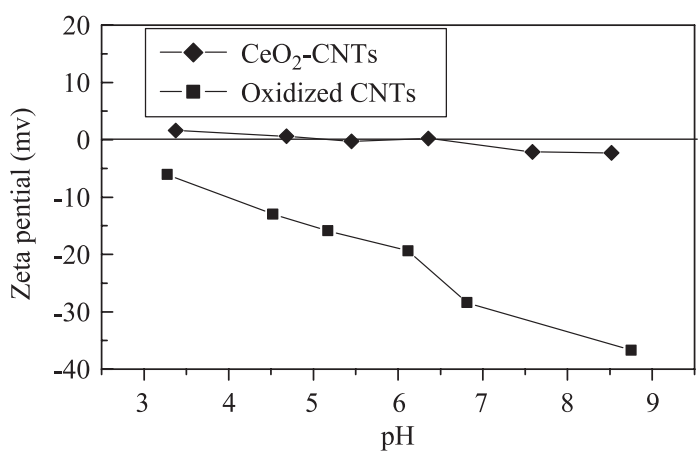

Fig. 3. Zeta potentials of $\mathrm{CeO}_{2}$-CNTs and oxidized CNTs.

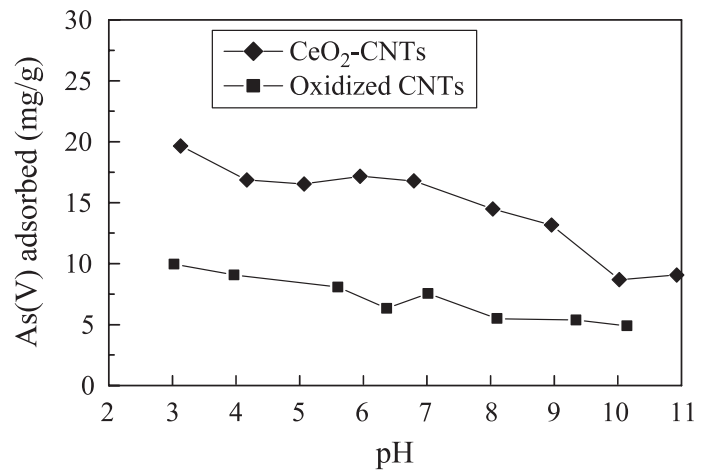

Fig. 4. The effect of $\mathrm{pH}$ on the adsorption $\left(C_{0}=20 \mathrm{mg} / \mathrm{L}, t=24 \mathrm{~h}\right.$, $m=0.025 \mathrm{~g})$.

surface. In the solution, the following chemical equilibriums exist:

$\mathrm{H}_{3} \mathrm{AsO}_{4}+\mathrm{H}_{2} \mathrm{O} \rightleftharpoons \mathrm{H}_{2} \mathrm{AsO}_{4}^{-}+\mathrm{H}_{3} \mathrm{O}^{+}$

$\mathrm{H}_{2} \mathrm{AsO}_{4}^{-}+\mathrm{H}_{2} \mathrm{O} \rightleftharpoons \mathrm{HAsO}_{4}^{2-}+\mathrm{H}_{3} \mathrm{O}^{+}$

$\mathrm{HAsO}_{4}^{2-}+\mathrm{H}_{2} \mathrm{O} \rightleftharpoons \mathrm{AsO}_{4}^{3-}+\mathrm{H}_{3} \mathrm{O}^{+}$

In the $\mathrm{pH}$ range $3-7, \mathrm{H}_{2} \mathrm{AsO}_{4}^{-}$is the predominant species, and in the $\mathrm{pH}$ range $7-10, \mathrm{HAsO}_{4}^{2-}$ is the predominant species. A mechanism for the adsorption of $\mathrm{As}(\mathrm{V})$ on goethite $(\alpha-\mathrm{FeOOH})$ in a two-step process has been proposed by Grossl et al. [18]. Based on this model, the mechanism for the adsorption of $\mathrm{As}(\mathrm{V})$ to $\mathrm{CeO}_{2}-\mathrm{CNTs}$ can be explained as follows:<smiles>CC(C)(O)OC(C)(C)O</smiles><smiles>CC(C)(O)OC(C)(C)O</smiles>

Fig. 5 shows adsorption isotherms of $\mathrm{CeO}_{2}-\mathrm{CNTs}$. The Freundlich model was employed for adsorption of $\mathrm{CeO}_{2}$ - 


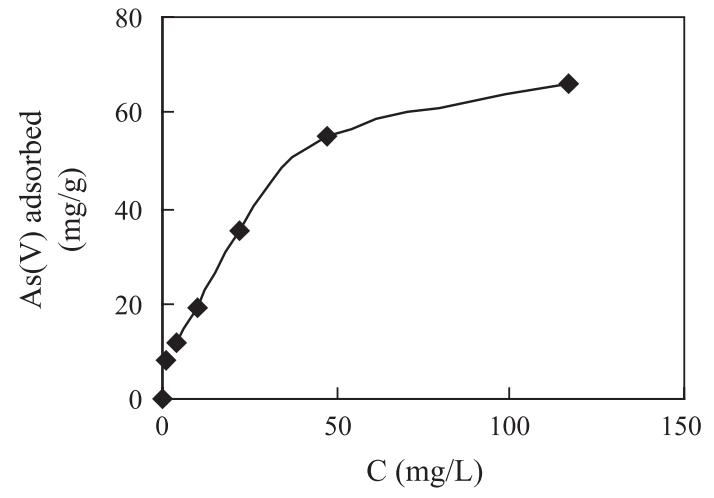

Fig. 5. Adsorption isotherms of $\mathrm{CeO}_{2}-\mathrm{CNTs}(m=0.025 \mathrm{~g}, t=24 \mathrm{~h}, \mathrm{pH} 3.1)$.

CNTs. Freunlich adsorption isotherm represents the relationship between the amount of adsorbate adsorbed by per unit mass of adsorbent $\left(q_{\mathrm{e}}\right)$ and the concentration of adsorbate at equilibrium $\left(C_{\mathrm{e}}\right)$ :

$q_{\mathrm{e}}=K C_{\mathrm{e}}^{\frac{1}{n}}$

or:

$\log q_{\mathrm{e}}=\log K+\frac{1}{n} \log C_{\mathrm{e}}$

$K$ and $n$ are constants representing the adsorption capacity and intensity of the adsorption, respectively. The experimental data fit the Freundlich adsorption isotherm well with a correlation coefficient of 0.964 .

$\mathrm{Ca}^{2+}$ and $\mathrm{Mg}^{2+}$ always exist in natural water. In order to assess the potential application of $\mathrm{CeO}_{2}$-CNTs for the removal of $\mathrm{As}(\mathrm{V})$ from natural water, adsorption capacity was evaluated as a function of $\mathrm{Ca}^{2+}$ and $\mathrm{Mg}^{2+}$ concentration. The adsorbent is aimed to be used in drinking water purification, therefore adsorption studies were carried out without $\mathrm{pH}$ adjustment. The results are shown in Fig. 6. It can be seen that $\mathrm{Ca}^{2+}$ and $\mathrm{Mg}^{2+}$ significantly enhance the adsorption capacity of $\mathrm{CeO}_{2}$-CNTs. An increase from 0 to $10 \mathrm{mg} / \mathrm{L}$ in the concentration of $\mathrm{Ca}^{2+}$ and $\mathrm{Mg}^{2+}$ results in an increase from 10 to 81.9 and $78.8 \mathrm{mg} / \mathrm{g}$ in the amount of $\mathrm{As}(\mathrm{V})$ adsorbed, respectively. When the concentrations of $\mathrm{Ca}^{2+}$ and $\mathrm{Mg}^{2+}$ exceed $10 \mathrm{mg} / \mathrm{L}$, the removal remains

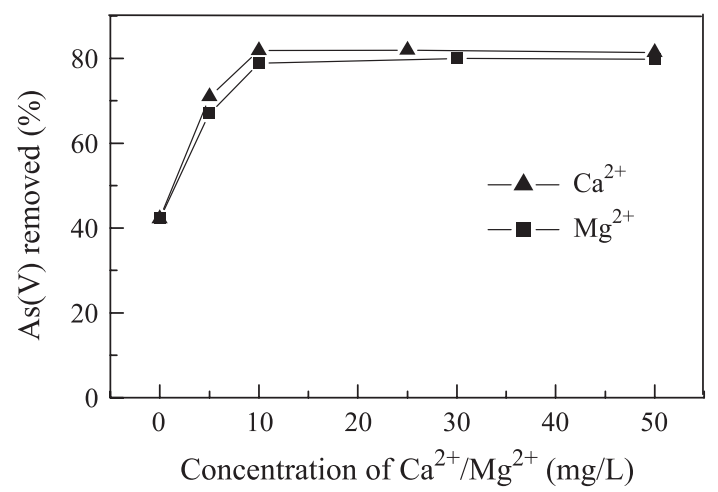

Fig. 6. The effect of $\mathrm{Ca}^{2+}$ and $\mathrm{Mg}^{2+}$ on adsorption $\left(C_{0}=20 \mathrm{mg} / \mathrm{L}, m=0.025\right.$ $\mathrm{g}, t=24 \mathrm{~h})$.

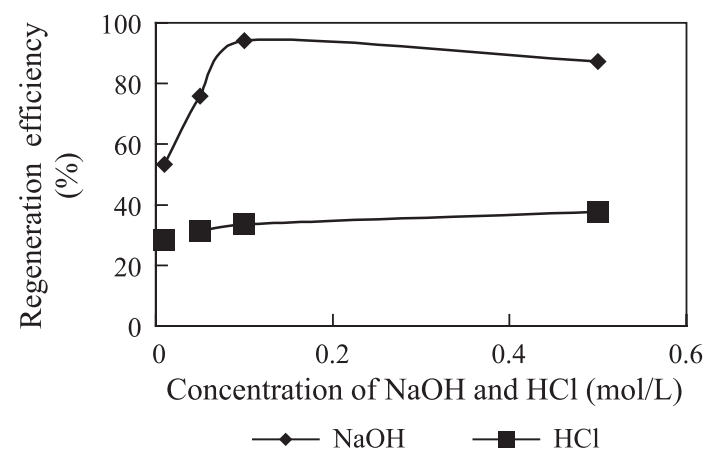

Fig. 7. The effect of $\mathrm{NaOH} / \mathrm{HCl}$ concentration on desorption.

constant, and $80 \% \mathrm{As}(\mathrm{V})$ removal was observed. The increased adsorption capacity with $\mathrm{Ca}^{2+}$ and $\mathrm{Mg}^{2+}$ existence can be explained by the ternary surface complex reaction $[19,20]$. The cations exchange with the surface groups first and then $\operatorname{As}(\mathrm{V})$ anions is combined to the liquid-solid interface, and the following surface complex forms:<smiles>CC(C)(C)OCCCCCCC#[W]</smiles>

The increased adsorption capacity with $\mathrm{Ca}^{2+}$ and $\mathrm{Mg}^{2+}$ existence suggests that $\mathrm{CeO}_{2}$-CNTs is a promising adsorbent for the removal of As from drinking water.

The applicability of adsorbents depends not only on the adsorption capacity, but also on the desorption property. $\mathrm{NaOH}$ and $\mathrm{HCl}$ were selected as regeneration agents in this work. In the desorption experiments, in order to show the desorption property of $\mathrm{CeO}_{2}$-CNTs as adsorbent for purification of natural water, first, $\operatorname{As}(\mathrm{V})$ was adsorbed from a $20 \mathrm{mg} / \mathrm{L}$ solution containing $10 \mathrm{mg} / \mathrm{L} \mathrm{Ca}^{2+}$. The effect of the concentration of regeneration agents on desorption efficiency is plotted in Fig. 7. The low desorption was observed using $\mathrm{HCl}$, and the regeneration efficiency is below $40 \%$. It can be seen that diluted $\mathrm{NaOH}$ is efficient for the regeneration. The regeneration efficiency reaches $94 \%$ when the concentration of $\mathrm{NaOH}$ reaches $0.1 \mathrm{~mol} / \mathrm{L}$, which suggests that $\mathrm{As}(\mathrm{V})$-loaded $\mathrm{CeO}_{2}$-CNTs can be efficiently regenerated by $\mathrm{NaOH}$ solution.

\section{Conclusion}

A novel adsorbent, ceria supported on CNTs, has been developed, and batch adsorption experiments were carried out to evaluate its adsorption capacity for $\mathrm{As}(\mathrm{V})$ from water. The experiments show that $\mathrm{CeO}_{2}$-CNTs have much higher zeta potentials than oxidized CNTs and can be expected to reduce the repulsion between its particles and negatively charged substances and enhance the removal of these substances from water. $\mathrm{CeO}_{2}$-CNTs adsorption is $\mathrm{pH}$ dependent due to the dependence of the surface charge of 
$\mathrm{CeO}_{2}-\mathrm{CNTs}$ on $\mathrm{pH}$ values. $\mathrm{Ca}^{2+}$ and $\mathrm{Mg}^{2+}$ significantly enhance its adsorption capacity due to the ternary surface complex reaction among solid surface, cations, and $\mathrm{As}(\mathrm{V})$ anions. Under natural $\mathrm{pH}$ conditions, an increase from 0 to $10 \mathrm{mg} / \mathrm{L}$ in the concentration of $\mathrm{Ca}^{2+}$ and $\mathrm{Mg}^{2+}$ results in an increase from 10 to 81.9 and $78.8 \mathrm{mg} / \mathrm{g}$ in the amount of $\mathrm{As}(\mathrm{V})$ adsorbed, respectively, which suggests that $\mathrm{CeO}_{2}-$ CNTs are a potential adsorbent for the removal of As from drinking water. The $\mathrm{As}(\mathrm{V})$-loaded adsorbent can be efficiently regenerated by diluted $\mathrm{NaOH}$, and a high regeneration efficiency of $94 \%$ was achieved using $0.1 \mathrm{~mol} / \mathrm{L}$ $\mathrm{NaOH}$.

\section{References}

[1] S. Iijima, Nature 354 (1991) 56.

[2] S.M. Lee, Y.H. Lee, Appl. Phys. Lett. 76 (2000) 2877.

[3] K. Fossheiheim, E.D. Tuset, T.W. Ebbesen, M.M.J. Treacy, J. Schwartz, Physica C 248 (1995) 195.

[4] T. Kuzumaki, K. Miyazawa, H. Ichinose, K. Ito, J. Mater. Res. 13 (1998) 2445

[5] J.M. Planeix, N. Coustel, B. Coq, et al., J. Chem. Soc. 116 (1994) 7935.
[6] G. Che, B.B. Lakshmi, E.R. Fisher, et al., Nature 393 (1998) 346.

[7] Y. Li, J. Ding, J. Chen, et al., Mater. Res. Bull. 37 (2002) 313.

[8] A.M. Raichur, V. Panvekar, Sep. Sci. Technol. 37 (2002) 1095.

[9] S.A. Wasay, S. Tokunaga, S.W. Park, Sep. Sci. Technol. 31 (1996) 1501.

[10] M.L. Pierce, C.B. Moore, Water Res. 16 (1982) 1247.

[11] T.M. Suzuki, M.L. Tanco, D.A.P. Tanaka, et al., Sep. Sci. Technol. 36 (2001) 103.

[12] R. Liu, J. Guo, H. Tang, J. Colloid Interface Sci 248 (2002) 268.

[13] S. Tokunaga, S.A. Wasay, S.W. Park, Water Sci. Technol. 35 (7) (1997) 71.

[14] S. Tokunaga, M.J. Harson, S.A. Wasay, Int. J. Environ. Stud. 48 (1995) 17.

[15] S.A. Wasay, M.J. Haron, A. Uchiumi, S. Tokunaga, Water Res. 30 (1996) 1143.

[16] S.A. Wasay, M.J. Haron, S. Tokunaga, Water Environ. Res. 68 (3) (1996) 295.

[17] C. Namasivayam, S. Senthikumar, Ind. Eng. Chem. Res. 37 (1998) 4816.

[18] P.R. Grossl, M. Eick, D.L. Sparks, S. Goldberg, C.C. Ainsworth, Environ. Sci. Technol. 31 (1997) 321.

[19] Z. Zhang, L. Liu, H. Zhao, et al., J. Colloid Interface Sci. 182 (1996) 158.

[20] W. Zhao, Z. Zhang, J. Ocean Univ. Qingdao 27 (2) (1997) 233, (In Chinese). 